Case Report

\title{
Late Presentation of Persistent Left Superior Caval Vein in a Univentricular Heart with Successful Transcutaneous Occlusion Using Cera Lifetech Atrial Septal Occluder
}

\author{
Iyad AL-Ammouri, ${ }^{1}$ Ahmad Alhourani, ${ }^{2}$ and Ayoub Innabi ${ }^{2}$ \\ ${ }^{1}$ Department of Pediatrics, Faculty of Medicine, University of Jordan, Amman 11940, Jordan \\ ${ }^{2}$ School of Medicine, University of Jordan, Amman 11940, Jordan \\ Correspondence should be addressed to Iyad AL-Ammouri; iyad72@hotmail.com
}

Received 10 August 2014; Accepted 19 October 2014; Published 6 November 2014

Academic Editor: Monvadi Barbara Srichai

Copyright ( 2014 Iyad AL-Ammouri et al. This is an open access article distributed under the Creative Commons Attribution License, which permits unrestricted use, distribution, and reproduction in any medium, provided the original work is properly cited.

We present a case of persistent left superior caval vein in a univentricular heart presenting with progressive and disabling cyanosis in a 35-year-old man eighteen years after his Kawashima operation. The vein was successfully occluded using an atrial septal occluder with significant improvement of symptoms and oxygen saturation.

\section{Introduction}

A persistent left superior caval vein with a reported incidence of $0.3 \%$ to $0.5 \%$ in the general population is considered the most common congenital venous anomaly of the thoracic venous return [1]. It has been reported in up to $12 \%$ of individuals with congenital heart abnormalities, such as septal defects, aortic coarctation, transposition of the great vessels, tetralogy of Fallot, and anomalous connections of the pulmonary veins [2-4].

The persistent left superior caval vein usually drains into the right atrium via the coronary sinus. In the rare case of coronary sinus ostial atresia, the left superior caval vein drains the coronary venous blood flow from the coronary sinus to the systemic venous circulation. These anomalies cause no shunts $[1,5]$. However, in $10-20 \%$ of cases, it drains to the left atrium either via unroofed coronary sinus, or in a straight line fashion into the roof of the left atrium, or the left superior pulmonary vein [6]. It is in this kind of abnormal connection where there is shunting that it may need to be occluded or ligated. Presentation of left superior caval vein in patients following single ventricle palliation has been reported several years after surgery [7]. We report a case where this anomaly was detected 18 years after surgery and was treated successfully by cardiac catheterization.

\section{Case Report}

A 35-year-old man with the diagnosis of mitral atresia, a double outlet right ventricle, pulmonary atresia with interrupted inferior caval vein, and azygous continuation to the right superior caval vein underwent a Blalock-Taussig shunt in early childhood and a Kawashima operation at the age of 17 at another institution. He presented to our clinic with progressive cyanosis and fatigue 18 years after his last surgical procedure. His oxygen saturation was $65 \%$.

Cardiac catheterization revealed left pulmonary artery stenosis and a decompressing vein from the right superior caval vein to the left superior caval vein which directly drains to the left atrium. Left pulmonary artery stenting was done via right internal jugular approach (Figures 1(a), 1(b), and 1(c)).

He underwent a second catheterization for occlusion of the left superior caval vein via left internal jugular approach. The anomalous vein measured 22 and $20 \mathrm{~mm}$ in AP and lateral projections, respectively. Balloon test occlusion resulted in immediate increase in oxygen saturation from $65 \%$ to $82 \%$ without drop of blood pressure. The mean pressure in the azygous vein remained at $9 \mathrm{mmHg}$; pressure in the left internal jugular vein increased to $11 \mathrm{mmHg}$ and dropped within a few minutes to $10 \mathrm{mmHg}$. Angiography showed good venous collateral drainage. 


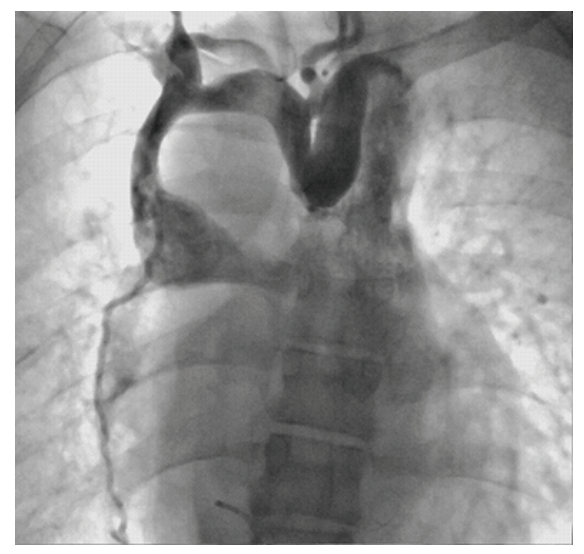

(a)

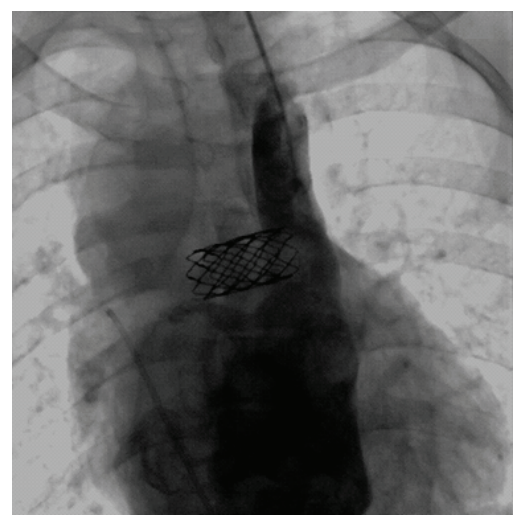

(d)

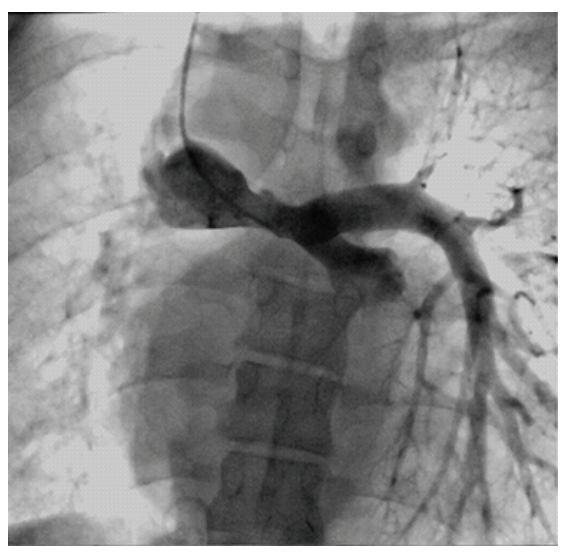

(b)

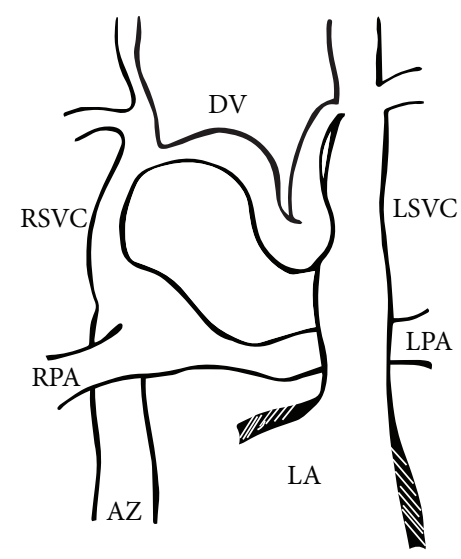

(c)

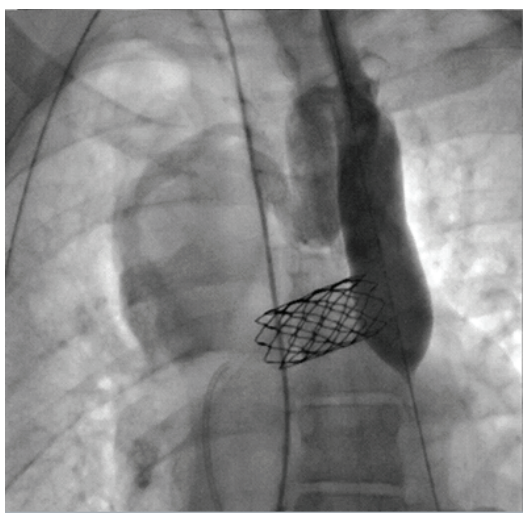

(e)

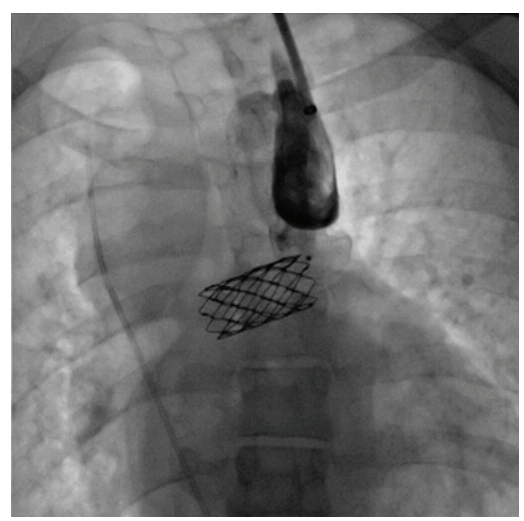

(f)

FIGURE 1: Vein angiography in a 35-year-old patient with univentricular heart 18 years following Kawashima operation. (a) Angiography through right internal jugular vein shows flow from the right superior caval vein to the left superior caval vein via a tortuous decompressing vein. (b) Angiography of the pulmonary artery shows mild narrowing of the left pulmonary artery. (c) Schematic of the venous anatomy. (d) During a separate procedure after stent placement in the left pulmonary artery, angiography through left jugular vein showing the large left superior caval draining to the left atrium. (e) Angiography during balloon test occlusion. (f) Angiography following device closure showing residual leak. (AZ: azygous vein, DV: decompressing vein, LA: left atrium, LPA: left pulmonary artery, LSVC: left superior caval vein, RPA: right pulmonary artery, and RSVC: right superior caval vein.)

The largest available vascular plug, $24 \mathrm{~mm}$ in diameter, failed to completely occlude the vessel, which was successfully occluded using a $24 \mathrm{~mm}$ ASD occluder (Cera Lifetech, China) via a $12 \mathrm{Fr}$ sheath. Upon completion of the procedure the patient had oxygen saturation of $80 \%$, left internal jugular pressure of $10 \mathrm{mmHg}$, and right superior caval vein and pulmonary artery pressure of $9 \mathrm{mmHg}$.

After occlusion, the patient had significant improvement of his exercise intolerance and fatigue. Follow-up hemodynamic study 12 months later showed no increase in venous pressure, no development of venous collaterals, and no decrease in his oxygen saturation.

\section{Discussion}

Generally, a persistent left superior caval vein draining into the right atrium through a coronary sinus has no hemodynamic consequence but draining into the left atrium creates a small obligatory right-to-left shunt [4]. Although this drainage to the left atrium is commonly asymptomatic, it may cause in some cases hypoxemia, cyanosis, clubbing of the nail bed, and some major complications like paradoxical embolization $[4,6,8]$. This may be more exaggerated in patients with univentricular hearts where the systemic venous pressure is always higher than left atrial pressure.

In our patient the diagnosis of a persistent left superior caval vein was made after presentation of progressive and symptomatic cyanosis 18 years after his cavopulmonary anastomosis. From the previous records of his operation at another institution it was unclear if the anomalous vein was identified. Since it is draining directly into the roof of the left atrium and the communicating vein to the right superior caval vein was long and tortuous, we tested by balloon occlusion to see if there is any effect on the cardiac output or the venous pressure before permanently occlude the vein. Balloon test occlusion has been well described before transcatheter occlusion of systemic venous anomalies [9].

In our patient there was no significant change in the venous or arterial pressure with significant improvement of oxygen saturation indicating a significant improvement 
of pulmonary blood flow. Because of the geometry of the vascular plug and the absence of retention discs in its design as well as the relatively large size of the vein, closure was not successful using vascular plug. Use of atrial septal occluder enabled secure placement due to the presence of retention discs. This was reported in previous reports as an off-label use of the atrial septal occlude [10-12].

\section{Conclusion}

Patients with single ventricle physiology should have regular follow-up and surveillance for right to left shunt, which can result in significant and progressive desaturation and deterioration of exercise tolerance. With the new and multiple selection of devices available in the recent years it has been possible to occlude many of the right to left shunts percutaneously.

\section{Conflict of Interests}

The authors declare no conflict of interests associated with this work.

\section{References}

[1] E. M. Cha and G. H. Khoury, "Persistent left superior vena cava," Radiology, vol. 103, no. 2, pp. 375-381, 1972.

[2] W. R. Meadows and J. T. Sharp, "Persistent left superior vena cava draining into the left atrium without arterial oxygen unsaturation," The American Journal of Cardiology, vol. 16, no. 2, pp. 273-279, 1965.

[3] T. C. Demos, H. V. Posniak, K. L. Pierce, M. C. Olson, and M. Muscato, "Venous anomalies of the thorax," American Journal of Roentgenology, vol. 182, no. 5, pp. 1139-1150, 2004.

[4] K. R. Trivedi, R. M. Freedom, S.-J. Yoo, B. W. McCrindle, and L. N. Benson, "Physiological impact and transcatheter treatment of the persisting left superior caval vein," Cardiology in the Young, vol. 12, no. 3, pp. 218-223, 2002.

[5] C. Kim, H. W. Goo, J. J. Yu, and T.-J. Yun, "Coronary sinus ostial atresia with persistent left superior vena cava demonstrated on cardiac CT in an infant with a functional single ventricle," Pediatric Radiology, vol. 42, no. 6, pp. 761-763, 2012.

[6] E. Troost, M. Gewillig, and W. Budts, "Percutaneous closure of a persistent left superior vena cava connected to the left atrium," International Journal of Cardiology, vol. 106, no. 3, pp. 365-366, 2006.

[7] A. F. Abdullah and S. Menahem, "Transcatheter closure of left superior vena cava for resolution of late cyanosis following Fontan palliation," Heart Lung and Circulation, vol. 15, no. 6, pp. 393-396, 2006.

[8] R. L. Geggel, S. B. Perry, E. D. Blume, and C. M. Baker, "Left superior vena cava connection to unroofed coronary sinus associated with positional cyanosis: successful transcatheter treatment using Gianturco-Grifka vascular occlusion device," Catheterization and Cardiovascular Interventions, vol. 48, pp. 369-373, 1999.

[9] M. R. Recto, F. Elbl, and E. Austin, “Transcatheter closure of large persistent left superior vena cava causing cyanosis in two patients post-Fontan operation utilizing the Gianturco Grifka vascular occlusion device," Catheterization and Cardiovascular Interventions, vol. 53, no. 3, pp. 398-404, 2001.

[10] M.-C. Seghaye, U. Wainwright, and G. von Bernuth, "Use of an Amplatzer ductal occluder to close a persistent left superior caval vein which reopened after a total cavopulmonary anastomosis," Cardiology in the Young, vol. 12, no. 1, pp. 81-83, 2002.

[11] E. Troost, M. Gewillig, and W. Budts, "Percutaneous closure of a persistent left superior vena cava connected to the left atrium," International Journal of Cardiology, vol. 106, no. 3, pp. 365-366, 2006.

[12] M. Zanchetta, M. Zennaro, R. Zecchel, D. Mancuso, and L. Pedon, "Use of the amplatzer ASD occluder for closing a persistent left vertical vein," CardioVascular and Interventional Radiology, vol. 32, no. 3, pp. 563-567, 2009. 


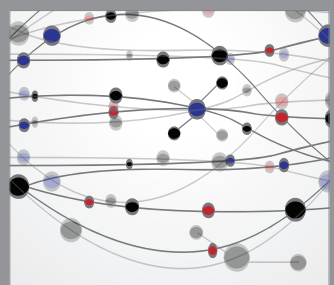

The Scientific World Journal
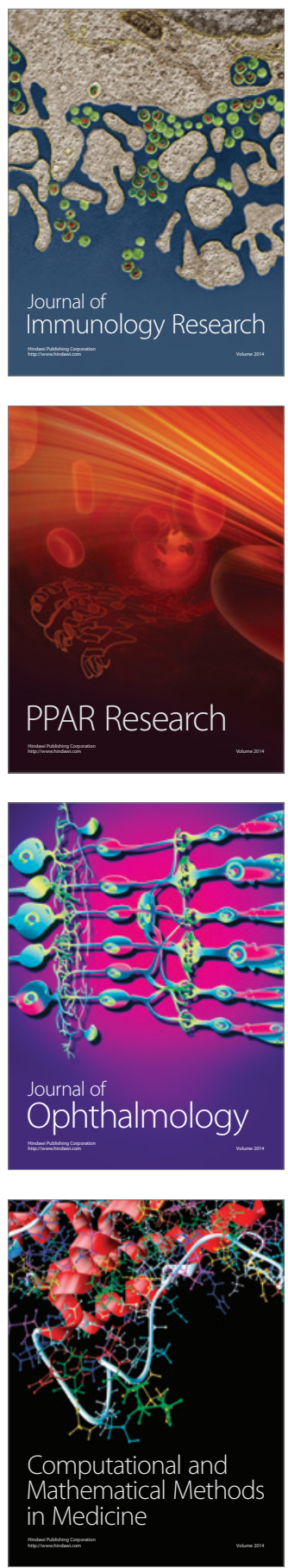

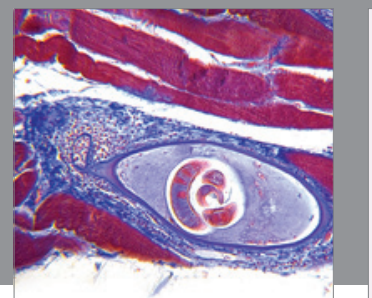

Gastroenterology

Research and Practice
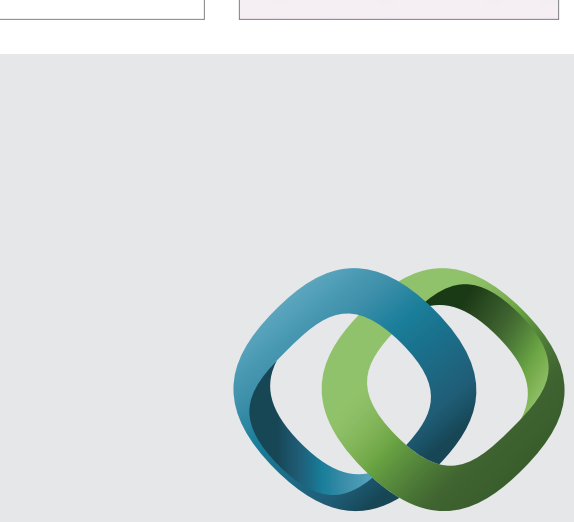

\section{Hindawi}

Submit your manuscripts at

http://www.hindawi.com
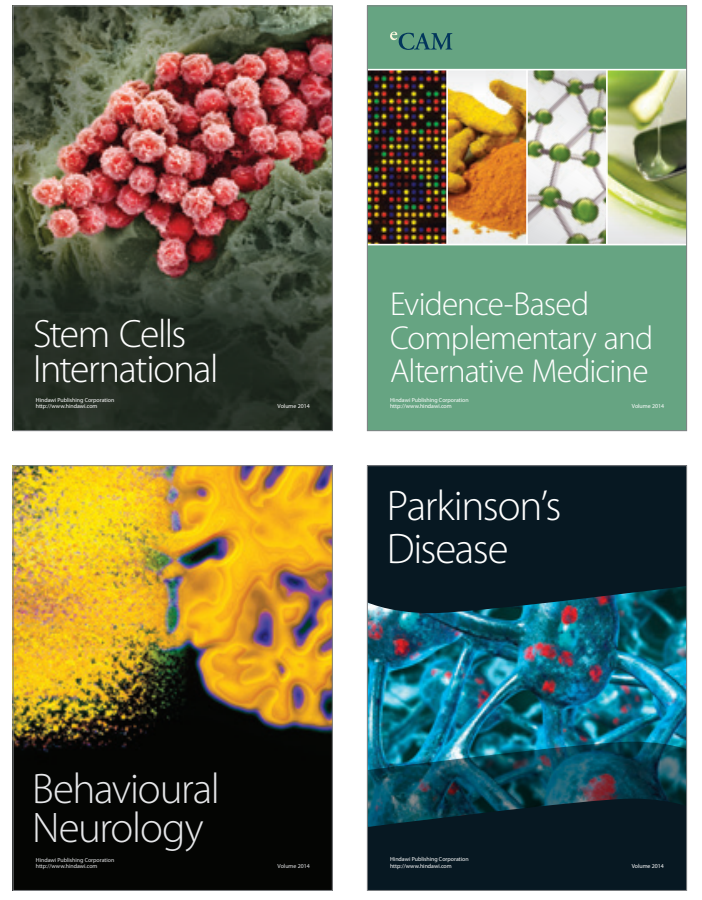
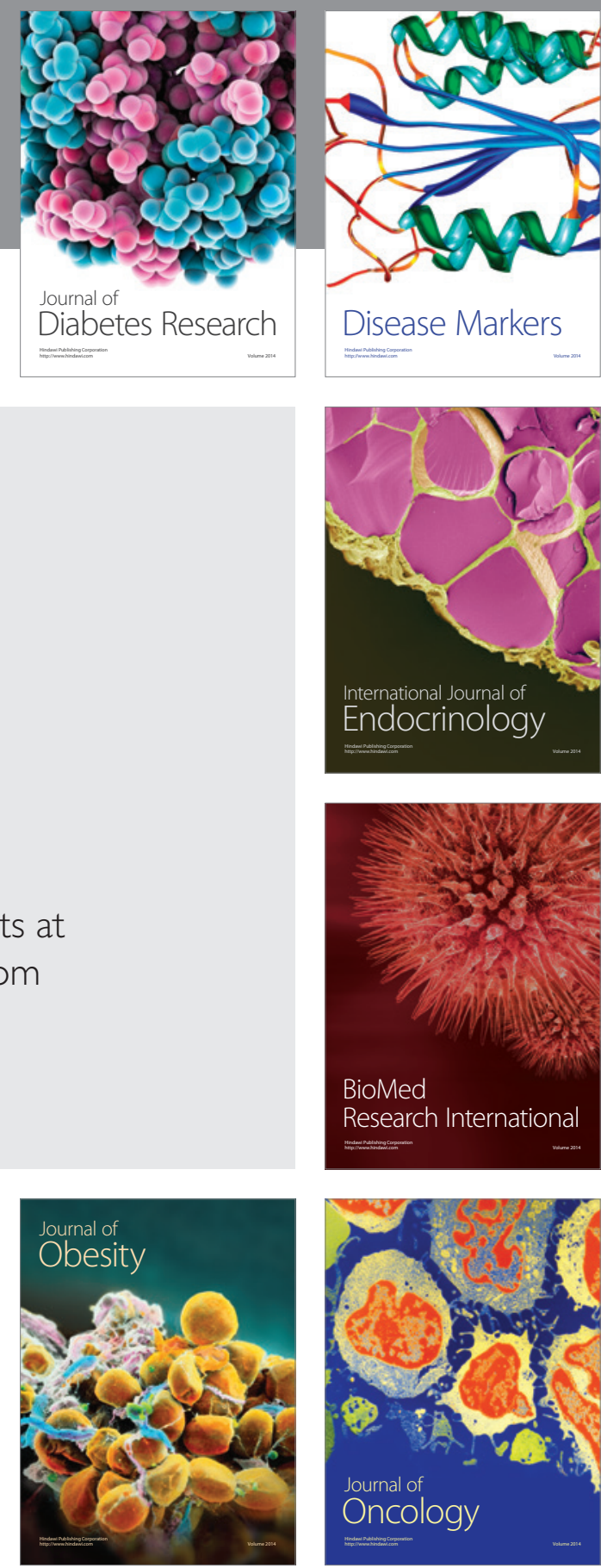

Disease Markers
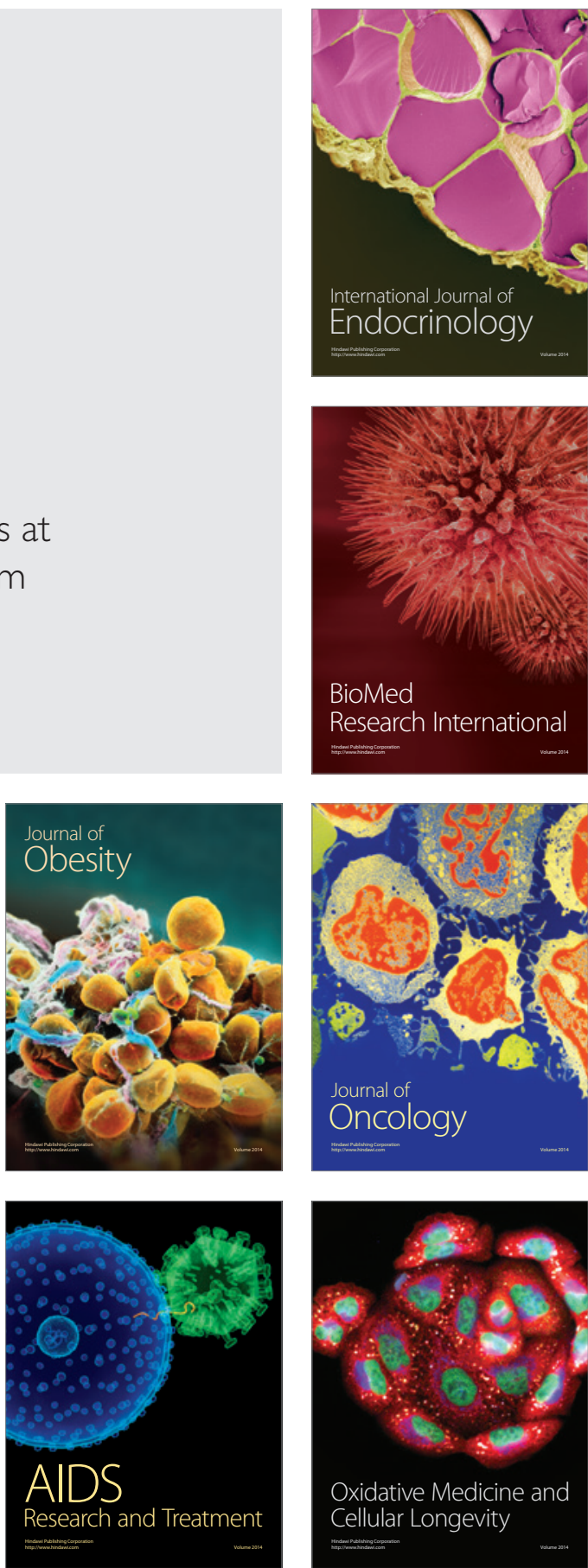